\title{
ISI POMPALI NEM KONTROLLÜ BİR KURUTUCUDA DEFNE YAPRAĞI KURUTULMASI
}

\author{
Mustafa AKTAȘ ${ }^{1}$, Emrah GÖNEN ${ }^{2}$ \\ ${ }^{1}$ Gazi Üniversitesi Teknoloji Fakültesi, Enerji Sistemleri Mühendisliği Bölümü, 06500, Teknikokullar, Ankara \\ ${ }^{2}$ Gazi Üniversitesi, Fen Bilimleri Enstitüsü, Teknikokullar, Ankara \\ mustafaaktas@gazi.edu.tr, emrah0640@hotmail.com
}

(Geliş/Received: 24.04.2013; Kabul/Accepted: 27.03.2014)

ÖZET

Bu çalışmada, kapalı devre 1sı pompalı bir kurutucuda defne yaprağı kurutulması ve sistem analizinin yapılması amaçlanmıştır. Türkiye'de büyük bir potansiyele sahip olan defne yaprağı Akdeniz ve Ege bölgelerinde yetişmektedir. Kurutma havası bağıl nemi, sıcaklığı ve hızı Programlanabilir Mantıksal Kontrolör (PLC) ekranından girilmiş ve set değerlerine göre kontrol edilmiştir. Isı pompalı kurutma sisteminde 6 farklı deney $40^{\circ} \mathrm{C}, 45^{\circ} \mathrm{C}$ ve $50^{\circ} \mathrm{C}$ kurutma havası sıcaklıklarında $1 \mathrm{~m} / \mathrm{s}$ ve $1,5 \mathrm{~m} / \mathrm{s}$ kurutma havası hızlarında yapılmıştır. Nem alma ünitesi kullanılarak deneyler esnasında kurutma havası bağıl nemi \% 4-11 aralığında tutulmuştur. Deneyler sonucunda tüm sistem için en yüksek performans katsayısı $\left(\mathrm{COP}_{\mathrm{ts}}\right)$ değeri $45^{\circ} \mathrm{C}$ ve $1,5 \mathrm{~m} / \mathrm{s}$ için 3,02 olarak hesaplanmıştır. Kurutulmuş defne yapraklarının su aktivitesi değerleri 0,49-0,55 aralığında ölçülmüştür.

Anahtar kelimeler: Kurutma, defne yaprağı, ısı pompası, nem kontrolü, nem alma

\section{BAY LEAVES DRYING IN A HUMIDITY CONTROLLED HEAT PUMP DRYER}

\begin{abstract}
In this study, drying of bay leaves and system analysing were aimed in a closed cycle heat pump dryer. The bay leaf that has a high potential in Turkey, grows in Mediterranean and Aegean regions. Drying air relative humidity, temperature and air velocity which were entered from Programmable Logic Controller (PLC) screen, controlled according to set value. Six different experiments were done in a heat pump dryer at $40{ }^{\circ} \mathrm{C}, 45^{\circ} \mathrm{C}$ and $50{ }^{\circ} \mathrm{C}$ drying air temperatures and $1 \mathrm{~m} / \mathrm{s}$ and $1.5 \mathrm{~m} / \mathrm{s}$ drying air velocities. Relative humidity of drying air was kept between the 4-11\% during the experiments by using dehumidification unit. The highest coefficient of performances $\left(\mathrm{COP}_{\mathrm{ts}}\right)$ of whole system was calculated as 3.02 at $45{ }^{\circ} \mathrm{C}-1 \mathrm{~m} / \mathrm{s}$ at the end of the experiments. Water activity values of dried bay leaves were measured between the $0.49-0.55$.
\end{abstract}

Keywords: Drying, bay leaves, heat pump, humidity control, dehumidification

\section{GIRIŞ̧ (INTRODUCTION)}

Kurutmadaki temel amaç gıdanın su aktivitesi değerini belli bir değere indirerek raf ömrünün uzatılmasıdır. Böylece ürün kurutularak mikrobiyal büyüme ve enzim aktivitesi engellenmiş olacaktır. Akdeniz defnesinin kullanılan kisımları yaprakları ve meyveleridir. Kurutulmuş defne yaprakları genellikle doğrudan doğruya konservelerde, çorba, balık ve et yemeklerinde baharat olarak kullanılmaktadır. Yaş veya kurutulmuş yapraklardan elde edilen eterik yağ gıda sanayinde temel kullanım yeri bulmaktadır. Ayrıca romatizma ağrılarını giderici ve terletici özellikleri nedeni ile kimya ve ilaç endüstrisinde de yararlanılmaktadır [1-3].

Literatürde defne yaprağı kurutulması ile ilgili az çalışma bulunmaktadır. Günhan vd. farklı şartlarda defne yapraklarını kurutarak matematiksel modellemesini yapmışlardır [4]. Hawlader ve Jahangeer, güneş enerjisi destekli 1sı pompalı kurutucunun ve su isiticisinın performansinı araştırmışlardır. Çalışmada, kompresör hızı arttığında özgül nem çekme oranının ve performans katsayısının azaldığ 1 gözlemlenmiştir [5].

Oktay (1997), 1S1 pompalı bir kurutucunun performansına etki eden parametreleri araştırmıştır. 
İncelemelerde by-pass hava oranı, toplam hava debisi ve egzoz debisi sistemin performansina etki eden anahtar parametreler olmuştur [6]. Demir vd. kurutulan defne yapraklarının bazı kalite parametrelerini incelemişlerdir [7]. Goh vd. kurutma uygulamaları için 1sı pompalı kurutucuları analiz etmiş ve değerlendirmiştir [8]. Teeboonma vd. isı pompalı meyve kurutucuların optimizasyonunu yapmışlardır [9]. Lee ve Kim, 1s1 pompalı bir kurutucuda ince dilimlenmiş kırmızı turpu kurutmuşlardır. Çalışma, ayrica 1sı pompalı kurutmanın, sicak havalı kurutmaya nazaran \% 58,9 $\quad-69,5$ oranında enerji tasarrufu sağladığını göstermiştir [10].

Kırmacı vd. yaptıkları çalıșmada dondurarak kurutma sistemi tasarlayıp çilek kurutma testlerini gerçekleştirmişlerdir [11]. Söylemez, kurutma sistemlerinde sistemdeki atık 1sıy1 kullanan 1S1 pompalı kurutucuların termo-ekonomik analizini yapmıştır. Sistem elemanları için optimum çalışma şartlarında COP değerini 2,3596 olarak hesaplamıştır [12].

Queiroz vd. yaptıkları çalışmada elektrik rezistanslı ve ısı pompalı olmak üzere iki farklı kurutucu kullanarak domates kurutmuşlar ve performanslarını araştırmışlardır. Sıcaklık, hava hızı ve domates tiplerinin etkilerini inceleyip isı pompalı kurutucunun efektif COP değerini 2,56-2,68 arasında tespit etmişlerdir [13].

Oktay ve Hepbaşlı mekanik 1sı pompalı bir kurutucunun performans değerlenmesini yapmışlardır. Yapılan çalışmada, kondenser ve eveporatör sıcaklıklarına bağlı olarak performans katsayısı 2,47 ile 3,95 arasında değişmiştir [14]. Fatouh vd. 1s1 pompalı kurutucu kullanılarak maydanoz, nane ve ebegümeci kurutmuşlardır [15].

Yağcıoğlu vd. farklı kurutma koşullarında defne yaprağının kurutma karakteristiklerini incelemişlerdir. Kontrollü koşullarla kurutmanın geleneksel kurutmaya göre birçok problemi ortadan kaldırdığ gözlemişlerdir. Ayrıca yaprakların $\% \quad 10$ nem içeriğine kadar kurutma zamanı, geleneksel kurutma işlemine göre $12 \mathrm{kez}$ ya da $40{ }^{\circ} \mathrm{C}$ sicaklıkta kurutma şartlarına göre $8 \mathrm{kez}$ daha kısaldığını ve hiçbir kayıp olmadığını ifade etmişlerdir [16]. Acar defne yaprağından uçucu yağ üretimi ve değerlendirilmesi konusunda yaptığı çalışmalarda; yaprakta kaliteyi etkileyen esas özelliklerin başında uçucu yağ miktarı ve bu yağın fizikokimyasal yapısının geldiğini belirtmiştir. Uçucu yağ miktarı ve bu yağın fizikokimyasal yapısı üzerine üretim yöresi, üretim zamanı, üretime alınan sürgünlerin yaşı gibi faktörlerin son derece etkili olduğunu ortaya koymuştur [17].

Tanker vd. defne yapraklarından \% 2 oranında uçucu yağ elde ettiklerini bildirmişlerdir. Defne uçucu yağının bileşiminde \% 45-50 oranında 1,8-sineol, \%
30 geraniol ve sitronellol, \% 5 öjenol, metilöjenol ve asetilojenol içerdiğini, bu bileşenlerin yanısıra uçucu yağda pinen başta olmak üzere oksijensiz terpenik maddelerin bulunduğunu belirtmişlerdir [18]. Müller vd. Almanya'da, kurutma sıcaklığının tıbbi adaçayının uçucu yağ üzerine etkilerini incelemişler ve araştırmada; 30-90 ${ }^{\circ} \mathrm{C}$ arasında değişen, numune ağırlığı ve kuruma oranları üzerine etkisi yapraklardaki nem \% 11'e düşünceye kadar incelenmiştir. $60{ }^{\circ} \mathrm{C}$ 'de uçucu yağ kaybına rastlanılmamış ve bu sıcaklıktan sonra uçucu yă̆ kaybının arttığını, $90{ }^{\circ} \mathrm{C}$ 'de \% 11'lik nem içeriğinde uçucu yağ kaybı \% 30'a ulaştığını, \% 11'lik nem içeriğinden sonra kurutma işlemine devam edildiği de $50{ }^{\circ} \mathrm{C}^{\prime}$ den daha yüksek sicaklıklarda uçucu yağ kaybının olduğu ve $90 \quad{ }^{\circ} \mathrm{C}$ 'de \% $\quad 90$ 'a ulaştığını belirtmişlerdir [19].

$\mathrm{Bu}$ çalışmada yapılacak olan kapalı devre teknik kurutma yöntemi ile; enerji tasarrufu ve yatırım maliyetlerinin düşürülmesi ve kurutulan ürünün de kaliteli olması hedeflenmiştir. Isı pompalı nem kontrollü kurutucuda defne yaprağı kurutularak çalışma şartlarının belirlenmesi ve bu optimum çalışma şartlarının enerji verimliliğine etkisi incelenmiştir. Kurutma havası hızı, sıcaklığı ve bağıl nemi kontrol edilerek ürünün bu değişimlerden etkilenmeden kurutulması hedeflenmiştir.

Defne yaprağı kurutulmasında kaliteye etki eden parametreler ürünün nem miktarı, ürünün rengi, tadı, ürünün büzülmesi ve besin değerleri vb. olarak sayılabilir. Bugüne kadar kurutma ile ilgili yapılan çalışmalarda gerek Ashrea yayınları ve standartlar gerekse de akademik çalışmalar kurutma sonrası ürün kalitesine ve kurutmada harcanan enerji miktarına dikkat çekmişlerdir. $\mathrm{Bu}$ nedenle makalede defne yaprağı kurutulması için daha önceki çalışmalarda rastlanmayan sıcaklık, bağıl nem, hava hızı ve ürün ağırlığı kontrollü $1 \mathrm{~s} 1$ pompalı kapalı bir sistem tasarlanmış ve enerji analizi yapılmıştır. Kurutma sonrası kaliteli ürün eldesi için sicaklık, bağıl nem, hava hızı ve ürün ağırlığının kontrol edilmesi gereklidir. Bu sistem tasarlanırken ürün kalitesine etki eden faktörler göz önünde bulundurulmuştur.

\section{TEORİK ANALIZ (THEORICAL ANALYSIS)}

Deneye başlamadan önce defne yapraklarının kuru ağırlığını belirleyebilmek için yaş defne yapraklarıyla ön çalışma yapılması gereklidir. Ön çalışma; etüv fırınında defne yapraklarının ağırlık değişimine göre nem kontrolünün belirlenmesi ve sabit sicaklıkta (103 $\pm 2{ }^{\circ} \mathrm{C}$ ) tutulan bu firında belirli aralıklarla defne yapraklarının tartılması ve ölçüm sonuçlarının değerlendirilmesi şeklinde yapılır.

Ön çalışmada alınan ölçüm sonuçları defne yaprağı ağırlık değişimi \%1 'den az olana kadar devam eder. Ağırlık ölçümlerine defne yapraklarının nem miktarı 
sabit kalana kadar alınmaya devam edilip; son ölçümler arası ağırlığın \% 1'den az olması durumunda defne yaprakları tam kuru kabul edilir. Üç kez etüv fırınında işlemler tekrarlanarak ölçüm sonuçlarının ortalaması alınıp ve ürünün kuru ağırlığı saptanır.

Defne yaprağı kuru esasa göre hesaplanan nem miktarı için;

$$
S O_{K A}=\frac{Y A-K A}{K A}
$$

eşitliği kullanılır.

Defne yaprağındaki yaş esasa göre hesaplanan nem miktarı için;

$$
S O_{Y A}=\frac{Y A-K A}{Y A}
$$

eşitliği kullanılır [20].

Kurutma prosesinde sürekli akışlı açık sistem için enerjinin korunumu en genel halde Eşitlik 3 ile ifade edilir [21].

$$
\dot{Q}-\dot{W}=\Sigma \dot{m}_{h} \cdot\left(h_{\varsigma}-h_{g}+\frac{V_{c}^{2}-V_{g}^{2}}{2}\right)
$$

Kurutma odasinda ve nem alma ünitesinde birim zamandaki 1sı değişimi Psikometrik diyagram kullanılarak aşağıdaki Eşitlik 4 ile hesaplanabilir.

$$
\dot{Q}=\dot{m}_{h} \cdot\left(h_{c}-h_{g}\right)
$$

Yoğuşturucuda havaya atılan ısı miktarı $\left(\dot{Q}_{Y}\right)$ Eşitlik 5 ile hesaplanabilir.

$$
\dot{Q}_{Y}=\dot{m}_{h} \cdot c_{h}\left(T_{\zeta}-T_{g}\right)
$$

Sistemde elektrik enerjisi tüketimi 1S1 pompasının kompresöründe meydana gelmektedir. Sistemde performans katsayısı aşağıdaki eşitlik yardımıyla hesaplanabilir.

$C O P_{h p, h}=\frac{\dot{Q}_{Y}}{\dot{Q}_{c}}$

Bütün sistem için performans katsayısının $\left(C O P_{t s}\right)$ hesaplanmasında tüketim ekipmanları için (kompresör, fan ve diğer ekipmanlar) aşağıdaki eşitlik kullanılır [22].

$$
C O P_{t s}=\frac{\dot{Q}_{Y}}{\dot{Q}_{c}+\dot{Q}_{\mathrm{f}}+\dot{Q}_{p}}
$$

Yapılan deneylerde ölçümlerde doğruluğu etkileyen en önemli etken deneyler sırasında oluşabilecek hatalardır. Ortaya çıkabilecek hatalar için toplam hata

$$
W_{R}=\left[\left(\frac{\partial R}{\partial x_{1}} w_{1}\right)^{2}+\left(\frac{\partial R}{\partial x_{2}} w_{2}\right)^{2}+\ldots \ldots \ldots . .+\left(\frac{\partial R}{\partial x_{n}} w_{n}\right)^{2}\right]^{1 / 2}
$$

eşitliği ile hesaplanabilir [23,24]. Eşitlik 8'de R ölçülmesi gereken büyüklük, $\mathrm{R}$ büyüklüğüne etki eden $\mathrm{n}$ adet bağımsız değişkenler ise $\mathrm{x}_{1}, \mathrm{x}_{2}, \mathrm{x}_{3}, \ldots \mathrm{x}_{\mathrm{n}}$ 'dir. Her bir bağımsız değişkene ait hata oranları $\mathrm{w}_{1}, \mathrm{w}_{2}, \mathrm{w}_{3}$, $\ldots \mathrm{W}_{\mathrm{n}}$ ve $\mathrm{R}$ büyüklüğünün toplam belirsizliği $\mathrm{W}_{\mathrm{R}}$ olarak ifade edilmiştir.

Tüm sistem için özgül nem çekme oranı $\left(\mathrm{SMER}_{\mathrm{ts}}\right)$, üründen buharlaştırılan $1 \mathrm{~kg}$ nem için harcanan toplam enerji miktarına oranı olarak tanımlanıp Eş. 9 ile verilmiştir.

$$
\operatorname{SMER}_{t s}=\frac{\dot{m}_{s u}}{\dot{W}_{c}+\dot{W}_{f}+\dot{W}_{p}}
$$

\section{DENEY SETİ (EXPERIMENTAL SET UP)}

Kurutma sisteminde kullanılan PLC kontrol sistemi; elde edilen deney verilerini bilgisayara aktarabilen ve kurutma havası sıcaklığını, bağıl nemini, hızını kontrol eden ve kurutulan defne yapraklarının ağırlık değişimini gösteren bir kontrol sistemidir. Kurutma sistemi kompresör (370 W), soğutucu akışkan R-134a, frekans invertörü, anemometre, yoğuşturucu, buharlaştırıcı, filtre, kılcal boru, fan $(160 \mathrm{~W} \& 990$ $\mathrm{m}^{3} / \mathrm{h}$ ), pompa $\left(370 \mathrm{~W}, 2,4 \mathrm{~m}^{3} / \mathrm{h}\right)$, su deposu (40 litre), anemometre, $20 \mathrm{~kg}$ ölçme kapasitesine sahip ağırlık ölçer, elektronik elektrik sayacı, kurutma odası ve PLC kontrol cihazından (sıcaklık ve ağırlık ölçümü, 1 MB uygulama hafizası artı $512 \mathrm{~K}$ font ve $3 \mathrm{MB}$ resim hafizası, LCD LED dokunmatik ekran, operatör paneli) oluşmaktadır Şekil 1'de sistemde havanın sıcaklık ve bağıl nemi değerlerinin ölçüm noktaları gösterilmiştir. 


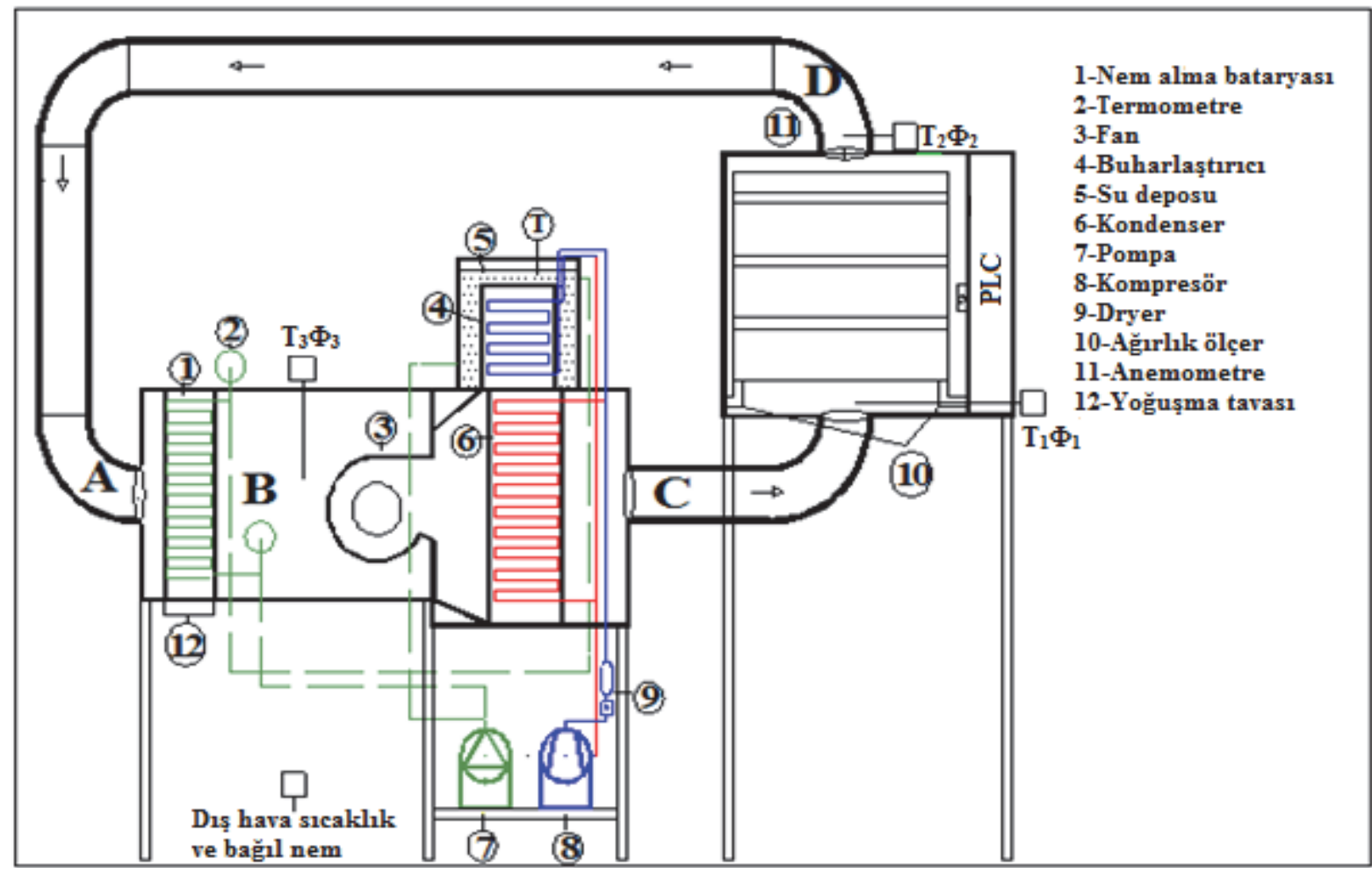

Şekil 1. Defne yaprağı kurutma sistemi (Bay leaf drying system)

Kurutma sisteminde 1sı pompası sisteminin yoğuşturucu kısmı enerji kaynağı olarak kullanılmakta, buharlaştırıcı kısmı ise depodaki suyun düşük sıcaklıkta muhafaza edilmesini sağlamaktadır. Sistemde kapalı devre dolaşan kurutma havası, üründe mevcut olan nemi bünyesine alarak, nemi artmakta ve buharlaştırıcı tarafında sağlanan soğuk su pompa ile 1sı değiştiricisine gönderilerek soğuk yüzeyde kurutma havasının nemini yoğuşturmaktadır. Kurutma sisteminde PLC kontrol cihazında ayarlanan sıcaklık, bağıl nem değeri sıcaklık-bağıl nem sensörü ile ve hava hızı anemometre ile ölçülüp set değerlerine göre kontrol edilmektedir. PLC'de girilen değer isıl çift ile ölçülen sicaklıktan büyükse kompresör devreye girmekte ve sıcaklık artışı sağlanmaktadır. Buharlaştırıcı tarafından soğutulan suyun istenildiğinde pompa yardımı ile dolaşımı sağlanıp, sistemde kurutma havasının bağıl neminin kontrolü sağlanmaktadır.

Nem alma ünitesi üzerinden geçen hava " $B$ " şartlarında yoğuşturucuda duyulur olarak isıtılarak sıcaklığı $\Delta \mathrm{T}$ kadar artarak "C" şartlarına gelir (Şekil 1' de $\mathrm{A}, \mathrm{B}, \mathrm{C}$ ve $\mathrm{D}$ noktaları gösterilmiştir). " $\mathrm{C}$ " şartlarında hava kurutma odasına girmekte defne yaprakları üzerinden geçerek “D” şartına gelmektedir. "D” şartlarında kurutma havasının özgül nemi bir miktar artmakta ve kuru termometre sicaklığ 1 da bir miktar düşmektedir. "D” şartlarındaki hava yalıtımlı hava kanalından akarak 1sı kaybından dolayı bir miktar soğuyarak nem alma ünitesine gelir (A şartı). Sistemdeki nemli hava PLC' ye girilmiş bağıl nem değerinden yüksek ise nem alma ünitesi devreye girerek kurutma havası nemi soğuk yüzeyde alınır.
"A" şartlarındaki nemli hava nem alma ünitesinden geçerek tekrar "B” şartlarına gelir.

Isı pompalı PLC kontrollü kurutma sisteminde PLC dijital ekranından ürün ağırlık değişimleri gözlenerek yapılan deneylerde ürün ağırlık değişimi kurutma sistemi durdurulmadan kayıt altına alınmıştır. Sistemde hava akışını, sıcaklık değerini, nem miktarını ve ürün ağırlığı Şekil 2'de görüldüğü gibi PLC kontrol sistemi ile kontrol edilebilmektedir.

Sistemde istenilen hava debisi PLC ekranından girilerek, oransal-integral-türevsel (PID) kontrol yapılarak istenilen hava debisi frekans invertörü ile sağlanmıştır. Sistemde ölçülen hava hızı değerine göre, PLC frekans invertörüne istenilen sinyali göndermiştir. Ürün kütle değişimi deneyler esnasında PLC ekranından takip edilmiştir.

\section{DENEYSEL YÖNTEM (EXPERIMENTAL PROCEDURE)}

Deneylere başlamadan önce Karadeniz Bölgesi'den temin edilen defne yapraklarının kuru ağırlığının belirlenmesi için ön hazırlık işlemleri yapılmıştır. Dal kısmı ile toplanmış olan taze defne yaprakları dallarından ayrılarak kuru ağırlığı belirlenmek üzere hazır hale getirilmiştir. Dallarından ayrılan defne yaprakları $103 \pm 2{ }^{\circ} \mathrm{C}^{\prime} \mathrm{de}$ sicaklık değerinde, kurutma firınında kurutulmaya başlanmıştır. İki ölçüm arasındaki fark \%1'den daha az olduğu durumda defne yaprakları kuru kabul edilmiştir. Bu işlem sırası yapılan üç deneyde de uygulanmıştır. 

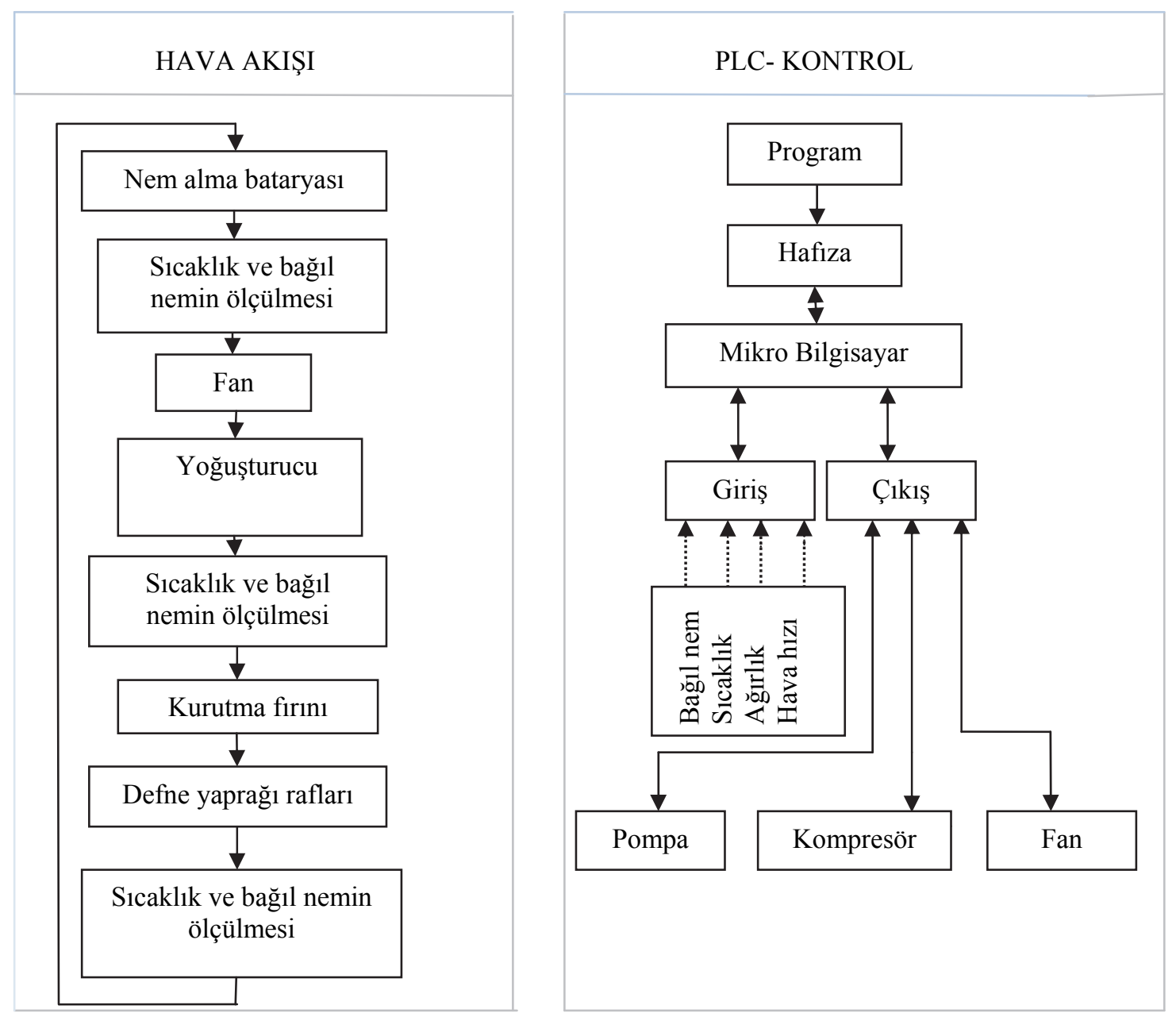

Şekil 2. Hava akışı ve PLC kontrol şeması (Schema of air flow and PLC control)

Başlangıç nem miktarları belirlenmiş olan defne yaprakları, 1s1 pompalı kondenzasyonlu kurutucuda kurutma kabinine yerleştirilerek, kurutma işlemine hazır hale getirilmiștir. Kurutma sisteminde defne yaprakları için uygun kurutma havası sıcaklık değerleri göz önünde bulundurularak, kurutma havası sicaklık değerleri $40^{\circ} \mathrm{C}, 45^{\circ} \mathrm{C}, 50^{\circ} \mathrm{C}$ kurutma havası hızları $1 \mathrm{~m} / \mathrm{s}$ ve $1,5 \mathrm{~m} / \mathrm{s}$ olarak belirlenmiştir. Kurutma sisteminde daha yüksek sicaklıklarda kurutma yapılabilirdi fakat defne yapraklarının daha yüksek sıcaklıklarda kurtulması durumunda yaprak kızarıklığ ve kırıklar oluşarak kalite kayıplarının olduğu literatürdeki çalışmalardan bilinmektedir. Ayrıca yüksek sıcaklıklarda yapılan defne yaprağı kurutmada yani $50{ }^{\circ} \mathrm{C}$ 'den daha yüksek sıcaklıklarda uçucu yağ kaybının olduğu bilinmektedir [19]. Sistemde daha düşük hızlarda kurutma yapıldığında kurutma süresi uzayacaktır. $1,5 \mathrm{~m} / \mathrm{s}^{\prime}$ den daha büyük hızlarda hızlı kütle transferinden dolayı defne yapraklarında istenmeyen büzülme ve kırılmaların olduğu yapılan ön deneylerde gözlemlenmiştir. Kurutma sistemlerinde ideal hava hızının 1-1,5 m/s olduğu bilinmektedir. $\mathrm{Bu}$ nedenlerden dolay $140-45-50{ }^{\circ} \mathrm{C}$ sicaklık ve $1-1,5 \mathrm{~m} / \mathrm{s}$ hava hızları denenmiştir. Bu sıcaklık değerleri için de 1sı pompası teknolojisinin çok uygun olması sistemin tasarımında önemli rol oynamıştır. Sistemde istenilen kurutma havası sıcaklığı ve hava hızı PLC kontrol cihazından ayarlanarak kurutma işlemi başlatılmıştır.

Kurutma işlemi sırasında defne yapraklarındaki ağırlık değişimi her yarım saatte bir ölçülmüş ve kaydedilmiştir. Yapılan bu deneyler esnasında kullanılan cihazlar ve teknik özellikleri Çizelge 1'de verilmiştir. Deneylerde ölçülen bir parametrenin (sıcaklık, bağıl nem vb.) sabit hatalar, rastgele hatalar ve imalat hataları dikkate alınarak farklı bağımsız değişkenlerden dolayı ortaya çıkan toplam hatası Eş. 8 kullanılarak hesaplanmış ve Çizelge 1'de verilmiştir. Örneğin su aktivitesi ölçümündeki toplam hata su aktivitesi ölçüm cihazının hassasiyetinden kaynaklanan hata ile bu değerin okunmasindan kaynaklanan hataların toplamıdır.

Kurutma sonrasında defne yapraklarının duyusal analizleri, nem miktarının tespiti ve su aktivitesi değerinin ölçümü yapılmıştır. Yapılan duyusal analizde defne yapraklarının görünümünde her hangi bir renk değişimi, tadında ve kokusunda her hangi bir bozulma gözlemlenmemiştir. El ile yapılan duyusal analizde ise kurutulmuş yapraklar ikiye katlandığında kırılgan olmadığı görülmüştür. 
Çizelge 1. Ekipmanların teknik özellikleri (Technical properties of equipments)

\begin{tabular}{|c|c|c|}
\hline Kullanılan cihaz & Teknik Özellikleri & Hata Analizi \\
\hline Dijital tartı & $\begin{array}{l}\text { En yüksek ölçülebilecek miktar } 6100 \mathrm{~g}, \text { ölçüm hassasiyeti } \\
\pm 0,01 \mathrm{~g}\end{array}$ & $\pm 0,0173 \mathrm{~g}$ \\
\hline $\begin{array}{l}\text { Bağıl nem ve sicaklık } \\
\text { transmitteri }\end{array}$ & $\begin{array}{l}\% 0-100 \text { bağıl nemde } \pm 2 \% \text { ölçüm hassasiyeti, }-40,+120 \\
{ }^{\circ} \mathrm{C} \text { sicaklıkta } \pm 1{ }^{\circ} \mathrm{C} \text { ölçüm hassasiyeti, çalışma sicaklığ } 1 \text { - } \\
10+60{ }^{\circ} \mathrm{C}\end{array}$ & $\begin{array}{l} \pm \% 0,0223 \mathrm{RH} \\
\quad \pm 1,118^{\circ} \mathrm{C}\end{array}$ \\
\hline $\begin{array}{l}\text { Hava hızı ve sıcaklık } \\
\text { ölçüm cihazı }\end{array}$ & $\begin{array}{l}\text { Sicaklık }-20,+70{ }^{\circ} \mathrm{C} \text {, hız } 0-20 \mathrm{~m} / \mathrm{s} \text { ölçüm hassasiyeti } \pm 0,01 \\
\mathrm{~m} / \mathrm{s}, \pm 0,1^{\circ} \mathrm{C}, \mathrm{NTC} \text { sensör }\end{array}$ & $\begin{array}{c} \pm 0,0141 \mathrm{~m} / \mathrm{s} \\
\pm 0,15^{\circ} \mathrm{C}\end{array}$ \\
\hline Su aktivitesi ölçüm cihazı & $\begin{array}{l}\text { Su aktivitesi } a_{w} \text { değeri } 0-1 \text { arasında olduğunda ölçüm } \\
\text { hassasiyeti } \pm 0,001\end{array}$ & $\pm 0,002$ \\
\hline Isıl çift & $\begin{array}{l}\text { Skala } 0-70{ }^{\circ} \mathrm{C} \text {, Besleme } 24 \mathrm{~V}-\mathrm{DC} \text {, Çıkış } 4-20 \mathrm{~mA} \text {, } \\
\text { hassasiyeti } \pm 0,1^{\circ} \mathrm{C}\end{array}$ & $\pm 0,173^{\circ} \mathrm{C}$ \\
\hline Ağırlık Ölçer & $\begin{array}{l}5 \text { kg Kapasite, } 40 \sim+80{ }^{\circ} \mathrm{C}, 5 \sim 12(\mathrm{DC}) \\
\text { hassasiyeti } \pm \% 0,02\end{array}$ & $\pm \% 0,0223$ \\
\hline
\end{tabular}

\section{DENEYSEL SONUÇLAR (EXPERIMENTAL RESULTS)}

Defne yapraklarının başlangıç nem miktarları kuru baza göre Eş. 1'den hesaplanarak 1,02 g su/g kuru madde olarak bulunmuştur. Kuru ağırlıkları belirlenen defne yaprakları PLC kontrollü kurutucuda farklı şartlarda kurutulmuştur. Deneyler esnasında defne yapraklarının kuru esasa göre son nem miktarı değişimi Şekil 3‘de görülmektedir.

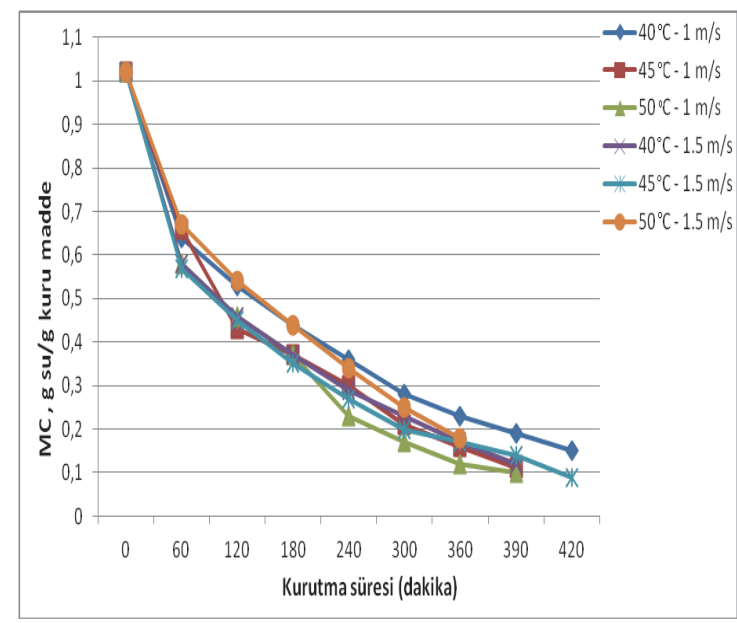

Şekil 3. Kurutma esnasında defne yapraklarının nem miktarının değişimi (Moisture content changes during the drying of bay leaves)

Şekil 3'de görüldüğü gibi defne yaprakları 6 farkl deneyde son nem miktarına ortalama 6,41 saatte indirilmiştir. Şekil 4' de yapılan deneylerde zamana göre kurutma havası bağıl nem değerlerinin değișimi görülmektedir.

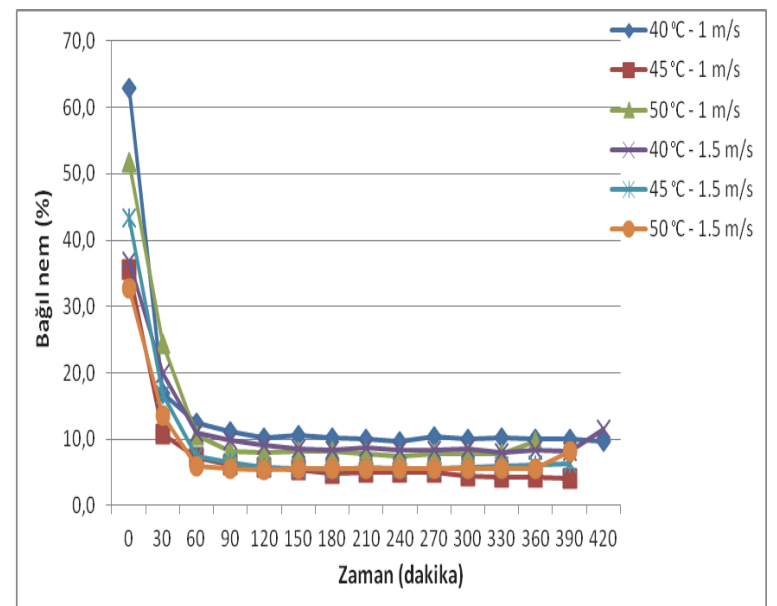

Şekil 4. Deneyler esnasında kurutma havası bağıl nem değişimi (Drying air relative humidity changes during the experiments)

Şekil 4'de görüldüğü gibi bağıl nem kontrollü olan kurutucuda üfleme havası bağıl nemi istenen değer aralığında tutularak havanın bünyesine nem alma kabiliyeti arttırılmıştır.

Isı pompalı kondenzasyonlu kurutma sisteminde yapılan deneylerde harcanan enerjinin büyük bir çoğunluğu kurutma sisteminin isitılmasında ve defne yapraklarının içerisindeki nemin buharlaştırılmasında harcanmıştır. Yapılan deneylerde tüketilen toplam enerji miktarı Şekil 5'de verilmiştir. 


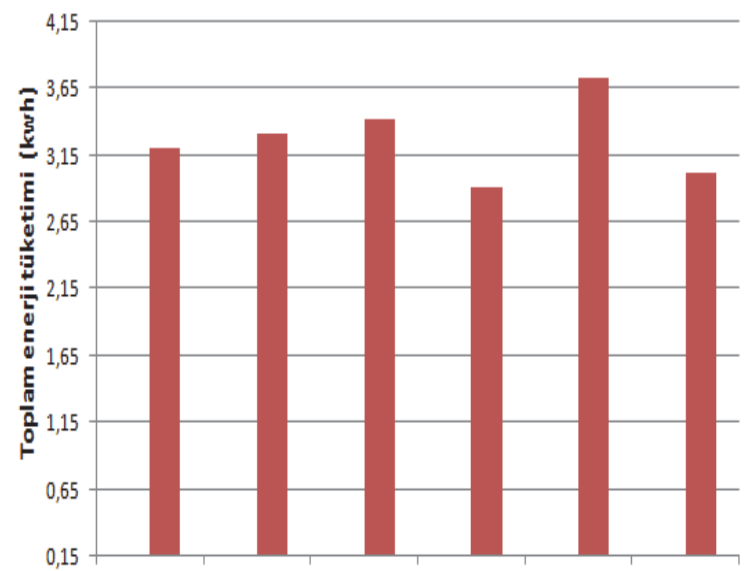

$40^{\circ} \mathrm{C}-1 \mathrm{~m} / \mathrm{s} \quad 45^{\circ} \mathrm{C}-1 \mathrm{~m} / \mathrm{s} \quad 50^{\circ} \mathrm{C}-1 \mathrm{~m} / \mathrm{s} \quad 40^{\circ} \mathrm{C}-1,5 \mathrm{~m} / \mathrm{s} \quad 45^{\circ} \mathrm{C}-1,5 \mathrm{~m} / \mathrm{s} \quad 50^{\circ} \mathrm{C}-1,5 \mathrm{~m} / \mathrm{s}$

Şekil 5. Deneylerde tüketilen toplam enerji (Consumed total energy at the experiments)

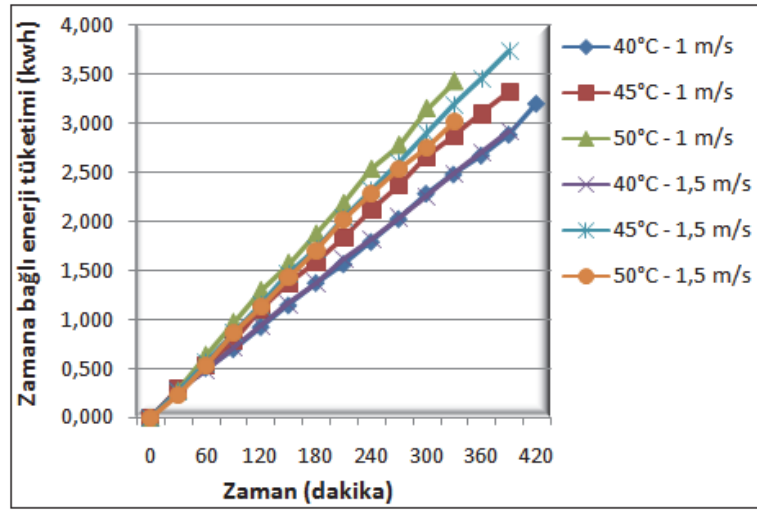

Şekil 6. Deneyler esnasında enerji tüketimi artışı (Consumed energy increasing during the experiments)

Deneylerde enerji tüketiminin zamana bağlı olarak dalgalanması set değerlerine göre kompresörün ve nem alma ünitesinin devreye girip çıkmasından kaynaklanmıştır. Şekil 6'da deneyler esnasında enerji tüketimi artışı görülmektedir.

Yapılan deneyler sonucunda tüm sistemin performans katsayıları $\left(\mathrm{COP}_{\mathrm{ts}}\right)$ Eş. 7 kullanılarak hesaplanmıştır. Tüm sistem performans katsayısının $\left(\mathrm{COP}_{\mathrm{ts}}\right)$ en yüksek olduğu deney $45{ }^{\circ} \mathrm{C}$ sıcaklığında $1,5 \mathrm{~m} / \mathrm{s}$ hava hızında hesaplanmıştır. Yapılan defne yaprağı kurutma deneylerinde elde edilen sonuçlar Çizelge 2 'de görülmektedir.

Şekil 6'da görüldüğü gibi deneylerde en fazla enerji tüketimi $45{ }^{\circ} \mathrm{C}$ ve $1,5 \mathrm{~m} / \mathrm{s}$ hava hızında yapılan deneyde olmuştur. Buna rağmen sistemde yapılan hesaplamalar sonucunda performans katsayısı en yüksek sistem $45{ }^{\circ} \mathrm{C}$ ve $1,5 \mathrm{~m} / \mathrm{s}$ ' de yapılan deneydir. Bunun sebebi kondenserden atılan 1S1 miktarının $\left(\dot{Q}_{Y}\right)$ diğer sistemlere göre daha fazla olmasıdır.

Defne yaprağında yapılan duyusal analiz sonucunda görünümünde, şeklinde, tadında ve kalitesinde her hangi bir bozulma gözlemlenmemiştir.

\section{SONUÇ VE ÖNERILER (RESULTS AND SUGGESTIONS)}

$\mathrm{Bu}$ çalışmada, PLC kontrollü, 1sı pompalı kurutma firını ile Türkiye için önemli bir ihraç ürünü olan defne yaprağı kurutulmuş, yapılan deneyler sonucunda aşağıdaki sonuçlar elde edilmiştir.

Kurutma esnasında sistemde kurutma odasından çıkan nemli hava nem alma ünitesinden geçirilerek havadaki nemin yoğuşturulması sağlanmıştır. Sistem kapalı devre nem kontrollü olarak çalıştırılarak enerji tüketimi azaltılmıştır.

Kurutulmuş defne yapraklarının su aktivitesi değerleri 0,49-0,55 aralığında ölçülmüştür. $\mathrm{Bu}$ metot ile ürün literatürdeki diğer çalışmalara göre daha kısa sürede kurutulmuş ve depolamaya hazır hale getirilmiştir.

$\mathrm{Bu}$ çalışma ile kurutulan defne yapraklarından daha kaliteli ürün elde edilebilmekte ve teknik kurutma ile yılın 12 ayı kurutma yapılabilmesi sağlanabilmektedir. $\mathrm{Bu}$ husus oldukça önemlidir, sebebi ise defne yaprağındaki yaprak ağırlıklarının fazla olması nedeniyle kış kesimlerinin tercih edilmesidir.

Çizelge 2. Deneysel sonuçlar (Experimental results)

\begin{tabular}{cccccc}
\hline Deneyler & $\mathbf{C O P}_{\text {ts }}$ & $\begin{array}{c}\mathbf{M C}_{\text {son }} \\
\text { g su/g kuru } \\
\text { madde }\end{array}$ & $\begin{array}{c}\text { Kurutma } \\
\text { süresi (h) }\end{array}$ & $\begin{array}{c}\text { Harcanan } \\
\text { toplam enerji } \\
\text { (kWh) }\end{array}$ & $\begin{array}{c}\mathbf{S M E R}_{\mathbf{t s}} \\
\mathbf{( g / k W h})\end{array}$ \\
\hline $40^{\circ} \mathrm{C}-1 \mathrm{~m} / \mathrm{s}$ & 2,41 & 0,15 & 7 & 3,204 & 40,39 \\
\hline $45^{\circ} \mathrm{C}-1 \mathrm{~m} / \mathrm{s}$ & 2,92 & 0,11 & 6,5 & 3,318 & 38,6 \\
\hline $50^{\circ} \mathrm{C}-1 \mathrm{~m} / \mathrm{s}$ & 2,34 & 0,1 & 6,5 & 3,423 & 37,98 \\
\hline $40^{\circ} \mathrm{C}-1,5 \mathrm{~m} / \mathrm{s}$ & 2,79 & 0,12 & 6,5 & 2,911 & 49,40 \\
\hline $45^{\circ} \mathrm{C}-1,5 \mathrm{~m} / \mathrm{s}$ & 3,02 & 0,1 & 6,5 & 3,735 & 39,40 \\
\hline $50^{\circ} \mathrm{C}-1,5 \mathrm{~m} / \mathrm{s}$ & 2,75 & 0,18 & 5,5 & 3,019 & 39,12 \\
\hline
\end{tabular}


Deneysel olarak analiz edilen 1sı pompalı, sicaklık, hava hızı ve nem kontrollü sistemde 6 farklı deney sonucunda performans katsayısı en yüksek sistem $45^{\circ} \mathrm{C}$ kurutma havası sıcaklığ 1 ve $1,5 \mathrm{~m} / \mathrm{s}$ hava hızının olduğu deneydir. $1,5 \mathrm{~m} / \mathrm{s}$ 'de yapılan deneylerde $1 \mathrm{~m} / \mathrm{s}$ hava hızına göre kondenserden 1sı atımı daha fazla olduğundan dolayı hava sıcaklığı istenilen değere daha kısa sürede gelerek sistem kompresörü durmuş bu da performans katsayısını arttırmıştır. $50^{\circ} \mathrm{C}-1,5$ $\mathrm{m} / \mathrm{s}$ deneyinde $50^{\circ} \mathrm{C}$ kurutma havası sicaklığını yakalayabilmek için $45^{\circ} \mathrm{C}-1,5 \mathrm{~m} / \mathrm{s}$ deneyine göre kompresör daha uzun süre devrede kalmış sistem nem alma moduna geçince de hava daha sıcak olduğundan pompa daha uzun süre devrede kalmıştır. $45^{\circ} \mathrm{C}-1,5$ $\mathrm{m} / \mathrm{s}$ deneyinin performans katsayısının $50^{\circ} \mathrm{C}-1,5 \mathrm{~m} / \mathrm{s}$ deneyinden daha yüksek olmasının nedeni budur.

Sistemde daha yüksek sicaklık ve hava hızlarında defne yaprakları kurutulabilir, bu durumda kurutma süresi kısalırken, kurutulan ürün kalitesinde bazı bozulmalar (yaprak kızarıklığı, büzülmeler ve kırıklar) olacaktır.

$\mathrm{Bu}$ çalışmada enerji verimliliği açısından defne yaprağı kurutulmasındaki en ideal sıcaklık değerinin $45^{\circ} \mathrm{C}$ olduğu kurutma hava hızının ise $1,5 \mathrm{~m} / \mathrm{s}$ olduğu tespit edilmiştir.

\section{SEMBOLLER (LIST OF SYMBOLS)}

\begin{tabular}{|c|c|}
\hline $\mathrm{c}_{\mathrm{h}}$ & Havanın özgül 1sısı [kJ/kg $\left.{ }^{\circ} \mathrm{C}\right]$ \\
\hline h & Entalpi $[\mathrm{kJ} / \mathrm{kg}]$ \\
\hline KA & Kurutma sonrası numune kütlesi, $[\mathrm{g}]$ \\
\hline$\dot{m}_{h}$ & Havanın kütlesel debisi $[\mathrm{kg} / \mathrm{s}]$ \\
\hline$\dot{Q}$ & Birim zamanda harcanan enerji $[\mathrm{kJ} / \mathrm{s}]$ \\
\hline$\dot{Q}_{c}$ & Kompresör gücü $[\mathrm{kJ} / \mathrm{s}]$ \\
\hline$\dot{Q}_{f}$ & Fan gücü $[\mathrm{kJ} / \mathrm{s}]$ \\
\hline$\dot{Q}_{p}$ & Pompa gücü $[\mathrm{kJ} / \mathrm{s}]$ \\
\hline $\mathrm{R}$ & Ölçülmesi gereken büyüklük \\
\hline$S O_{K A}$ & $\begin{array}{l}\text { Kuru maddeye göre ürün içerisindeki } \\
\text { su miktarı [g su/g kuru madde] }\end{array}$ \\
\hline$S O_{Y A}$ & $\begin{array}{l}\text { Yaş maddeye göre ürün içerisindeki su } \\
\text { miktarı }[\mathrm{g} \mathrm{su} / \mathrm{g} \text { yaş madde }]\end{array}$ \\
\hline $\mathrm{T}$ & Sicaklık $\left[{ }^{\circ} \mathrm{C}\right]$ \\
\hline $\mathrm{V}$ & $\mathrm{H} 1 \mathrm{z}[\mathrm{m} / \mathrm{s}]$ \\
\hline $\mathrm{W}$ & Hata oran1 \\
\hline$\dot{W}$ & Birim zamanda yapılan iş $[\mathrm{kJ} / \mathrm{s}]$ \\
\hline $\mathrm{W}_{\mathrm{R}}$ & $\mathrm{R}$ büyüklüğünün toplam belirsizliği \\
\hline $\mathrm{x}$ & Bağımsız değişken \\
\hline YA & Kurutma öncesi numune kütlesi, [g] \\
\hline
\end{tabular}

\section{TEŞEKKÜR (ACKNOWLEDGEMENTS)}

07/2010-22 kodlu projeye vermiş oldukları desteklerinden dolayı Gazi Üniversitesi Bilimsel Araştırma Projeleri Birimi’ne teşekkür ederiz.

\section{KAYNAKLAR (REFERENCES)}

1. Göker, Y., ve Acar, İ., "Orman Yan Ürünlerinden Akdeniz Defnesi (Laurus nobilis L.)", İstanbul Üniversitesi Orman Fakültesi Dergisi, 33(1): 124-140, 1983.

2. Acar, İ., "Defne (Laurus nobilis L.) Yaprağı ve Yaprak Eterik Yağının Üretilmesi ve Değerlendirilmesi”, Ormancılık Araştırma Enstitüsü Yayınları, Teknik Bülten Serisi, 186, Ankara,: 10,11, 1987.

3. Bozkurt, Y. ve Göker, Y., "Orman Ürünlerinden Faydalanma Ders Kitabı", İstanbul Üniversitesi Orman Fakültesi Yayınları, İ.Ü. Yayın No: 2840, Yayın No:297, 402, İstanbul, 1981

4. Günhan, T., Demir, V., Hancioglu E., Hepbasli, A.," Mathematical modelling of drying of bay leaves", Energy Conversion and Management, 46, 1667-1679, 2005.

5. Hawlader, M., N., A., Jahangeer, K., A., "Solar heat pump drying and water heating in the tropics", Solar Energy, 80(5): 492-499, 2006.

6. Oktay, Z. "Isı pompası destekli bir kurutucunun performansına etkiyen etkenlerin araştırılması" Makine Mühendisleri Yayını, Teskon Program Bildirileri, Soğ 047, 750-759, (1997).

7. Demir, V.,. Günhan, T., Yağcioglu, A.K., Değirmencioğlu A., "Mathematical Modelling and the Determination of Some Quality Parameters of Air-dried Bay Leaves", Biosystems Engineering, 88 (3), 325-335, 2004.

8. Goh, L. J., Othman, M., Y., Mat, S., Ruslan, H., Sopian, K., "Review of heat pump systems for drying application", Renewable and Sustainable Energy Reviews, 15, 4788-4796, 2011.

9. Teeboonma U, Tiansuwan J, Soponronnarit S. "Optimization of heat pump fruit dryers", Journal of Food Engineering, 59:369-77, 2003.

10. Lee, K. H., Kim, O. J., Investigation On Drying Performance And Energy Savings Of The BatchType Heat Pump Dryer, Drying Technology, 27, 565-573, 2009.

11. Kirmac1, V., Usta H., Menlik T., "An Experimental Study on Freeze-Drying Behavior of Strawberries", Drying Technology, 26:12, 1570-1576, 2008.

12. Söylemez, M., S., "Optimum heat pump in drying systems with waste heatrecovery", Journal of Food Engineering, 74: 292-298, 2006.

13. Queiroz, R., Gabas, A. L., Telis, V. R. N., "Drying Kinetics of Tomato by Using Electric Resistance and Heat Pump Dryers", Drying Technology, 22, 1603-1620, 2004.

14. Oktay Z., Hepbaşlı A., "Performance evaluation of a heat pump assisted mechanical opener dryer", Energy Conversion and Management, 44: 1193-1207, 2003.

15. Fatouh, M., Metwally, A., B., Helali A., Shedid, M.,H., "Herbs drying using a heat 
pump dryer", Energy Con. and Man., 47(1516): 2629-2643, 2006.

16. Yağcioglu, A., Degirmencioğlu, A., Çagatay, F., "Drying Characteristics of Laruel Leaves Under Different Drying Conditions', 7th International Congress on Agricaltural Mechanisation and Energy, Adana, 565-569, 1999.

17. Acar, İ.,'Defne (Laurus nobilis L.) Yaprağı ve Yaprak Eterik Yağının Üretilmesi ve Değerlendirilmesi”, Orm. Araş. Ens. Yayınları, Seri No. 186, Ankara, 1988.

18. Tanker, M. ve Tanker, N., Farmakognozi 2, Reman Basımevi, İstanbul, 1976.

19. Muller, J., Köll-Weber, M., Kraus, W., " Effect of Drying on the Essential Oil of Salvia Officinalis", Planta Medica, No: 58 (1): 78, 1992.
20. Aktaş, M., Kara M., Ç., "Güneş enerjisi ve Isı Pompalı Kurutucuda Dilimlenmiş Kivi Kurutulması", Journal of the Faculty of Engineering and Architecture of Gazi University, 28:4, 733-741, 2013.

21. Çengel, Y., A., Boles, M., A., "Mühendislik Yaklaşımıyla Termodinamik", Güven Bilimsel Yayınları, 230-232, 2008.

22. Ceylan, İ., ve Aktaş, M., "Isı Pompası Destekli Bir Kurutucuda Findık Kurutulması", Journal of the Faculty of Engineering and Architecture of Gazi University, 23:1, 215-222, 2008.

23. Holman JP., "Experimental Methods for Engineers", Sigapore: McGraw-Hill; 1994.

24. Kavak Akpınar E., 'Drying of Mint Leaves in a Solar Dryer and Under Open Sun: Modelling, Performance Analyses', Energy Con. and Man., 51 2407-2418, 2010. 
